\title{
EL PROYECTO DE ACTO LEGISLATIVO 192 DE 2012 Y SUS IMPLICACIONES EN LA JURISDICCIÓN PENAL MILITAR.
}

\section{R. Camilo Andrés SuÁrez Aldana*}

La deferencia y generosidad de la Universidad Sergio Arboleda, y en particular del Doctor Fernando Velásquez, nos permite expresar la voz de la Justicia Penal Militar en tan álgida temática en el recinto más adecuado para construir y fortalecer el sistema de administración de justicia, como es la academia. En nombre del Tribunal Superior Militar y de los integrantes de la jurisdicción especializada agradezco a esta casa de estudios el espacio que se nos ha otorgado en este importante evento.

Proponer una reforma al fuero militar y consecuentemente de la Justicia Penal Militar en Colombia, sugiere advertir que cualquier modificación que se intente en esta materia debe ser coherente con la realidad de nuestra nación, esto es, se debe pensar y reflexionar acerca del país en que vivimos, reconocer cuál es el contexto Colombiano y la situación que por décadas hemos enfrentado en materia de orden público; de igual forma analizar cuál es el nivel del conflicto interno - por demás prolongado e intenso- así como considerar el tipo de amenaza que realmente ha tenido que enfrentar y desafía la Fuerza Pública. Esto sugiere verificar la potencialidad, capacidad de estructura, organización y daño de los grupos al margen de la ley.

Sin duda una respuesta a estos interrogantes no requiere esfuerzo, basta con evocar lo que fue nuestro proceso independentista, la guerra de los mil días, la violencia que se desató y aún no cesa

* Presidente del Tribunal Superior Militar. 
desde 1948, que derivó en el surgimiento de las denominadas guerrillas, factores generadores de violencia como el narcotráfico, las autodefensas ilegales (o el mal llamado paramilitarismo), el fenómeno terrorista hoy lamentablemente presente, o sino miremos lo que ocurrió sólo hace unos días en el Cauca, el Catatumbo, Vista Hermosa, Meta, por sólo citar unos ejemplos.

Sabido es que el Estado Colombiano, por décadas, ha tenido que enfrentar con fuerza militar un enemigo real que se fue fortaleciendo como las FARC, el ELN, las AUC, tanto así que frente a la complejidad, intensidad y dinámica del conflicto se replanteó la forma de maniobrar bajo el concepto de operaciones conjuntas y combinadas. Sin embargo, paradójicamente en la medida en que se intensificaba el conflicto, de manera inversamente proporcional se ha reducido el ámbito de aplicación del fuero castrense.

Lo citado en precedencia nos permite afirmar que cuando se trata de una reforma al fuero militar y a la jurisdicción especializada no se puede tomar como patrón de comparación otras latitudes, realidades sociales, política y jurídicamente diferentes a la nuestra, como acontece cuando se pretende comparar la aplicación del fuero y el ámbito de competencia de la jurisdicción castrense bajo parámetros de países desarrollados y en paz como Holanda, Suecia, Suiza, o la propia Norte América; o, a contrario, confrontarla en escenarios donde las justicias militares tuvieron protagonismo en el seno de dictaduras. Nuestra historia, tradición y realidad es absolutamente distinta; en consecuencia demanda un juicio de valoración coherente con nuestra situación. Por ejemplo, es deber del operador jurídico aplicar en el juicio de imputación o de responsabilidad de un miembro de la Fuerza Pública que actúa en una operación militar y dentro del contexto del conflicto interno, las reglas de conducción de hostilidades, invocar los catálogos de principios que regulan los conflictos dispuestos en el marco del Derecho Internacional Humanitario ${ }^{1}$, atender los preceptos de interpretación y de aplicación en el derecho interno. Sin embargo, la praxis judicial nos demuestra que ello no se hace o se dilucida indebidamente.

Investigaciones y juicios adelantados en Justicia Militar u Ordinaria contra miembros de la Fuerza Pública presentan soluciones diversas

${ }^{1}$ Derecho de Ginebra. Derecho de la Haya. Protocolo II, Artículo 3 común a los Convenios de Ginebra. 
y controversiales, máxime cuando acontece el fenómeno de la investigación paralela o concurrente, esto es, cuando una misma situación fáctica es investigada en las dos jurisdicciones, lo que contribuye a generar una violación al principio del non bis in idem y de suyo dar paso a la inseguridad jurídica por la falta de precisión conceptual respecto del alcance del fuero militar, los elementos que lo componen y lo que significa relación con el servicio.

Recordemos que en la tradición democrática colombiana el fuero militar ha tenido vocación constitucional, así, por citar sólo dos momentos en la Constitución de 1886 se consagraba en el artículo 170: "De los delitos cometidos por los militares en servicio activo y en relación con el mismo servicio conocerán las cortes marciales o tribunales militares, con arreglo a las prescripciones del código penal militar". Y en la Constitución Política de 1991 se prevé en los artículos 116, 221 y 250, respectivamente, quiénes administran justicia, ubicando allí a la jurisdicción penal militar, consecuentemente el ámbito de aplicación del fuero militar y seguidamente el postulado que precisa que los delitos cometidos por los miembros de la Fuerza Pública en servicio activo y en relación con el servicio, el ejercicio de la acción penal no lo detenta la justicia ordinaria, para el caso la Fiscalía General de la Nación, sino la jurisdicción penal militar².

En lo sustancial evoquemos lo que dispone el Constituyente Primario: "Artículo 116. La Corte Constitucional, la Corte Suprema de Justicia, el Consejo de Estado, el Consejo Superior de la Judicatura, la Fiscalía General de la Nación, los Tribunales y los Jueces, administran justicia. También lo hace la justicia penal militar (...)” (Subrayado nuestro). "Artículo 221. Modificado. Acto Legislativo 02 de 1995. Texto original: "De los delitos cometidos por los miembros de la Fuerza Pública en servicio activo, y en relación con el mismo servicio, conocerán las cortes marciales o tribunales militares, con arreglo a las prescripciones del Código Penal Militar". Al final de este artículo se incluyó una frase: Artículo $1^{\circ}$. El artículo 221 de la Constitución Política de Colombia, quedará así: "De los delitos cometidos por los miembros de la fuerza pública en servicio activo, y en relación con el mismo servicio, conocerán las Cortes Marciales o Tribunales Militares, con arreglo a las prescripciones del Código Penal Militar. Tales Cortes o Tribunales estarán integrados por miembros de la Fuerza Pública en servicio activo o en retiro". También, el Artículo 250 (Acto legislativo 03 de 2002) en lo sustancial: “(...) Se

${ }^{2}$ C- 591 de 2005 M. P. Clara Inés Vargas. 
exceptúan los delitos cometidos por los miembros de la fuerza pública en servicio activo y en relación con el mismo servicio...".

Obsérvese que tanto en la Constitución de 1886 como en la de 1991 hay una constante ${ }^{3}$ que limita el fuero militar y corresponde al factor objetivo "relación con el servicio", elemento que fuera objeto de estudio por la Corte Constitucional en 1997 mediante la sentencia C- 358 del 5 de agosto, donde se estableció que el fuero lo componen dos elementos: el subjetivo personal y el objetivo funcional. Respecto de aquél, no existe dificultad pues se acredita a través del acto administrativo que verifica la condición de miembro de la Fuerza Publica en servicio activo en el momento del hecho, pero, respecto de este último, sí se presenta complejidad de tal magnitud que hoy nos avoca a una reforma constitucional que precise el alcance del fuero, particularmente que determine el elemento funcional, el derecho aplicable y la autoridad judicial llamada a imputarlo.

En este punto de nuestra intervención llamamos la atención sobre un cuestionamiento que nos hemos planteado por años, máxime como funcionarios de justicia militar: corresponde a si la dificultad en la aplicación del fuero militar, tanto en justicia ordinaria como militar, es un problema normativo o interpretativo. Pareciera que el concepto "relación con el servicio" es tan maleable o restringido según sea la capacidad de entendimiento, comprensión, precisión o imprecisión conceptual del intérprete, cuando no es que termina legislándose con la doctrina militar o las reglas de enfrentamiento en las decisiones judiciales, con lo que se mengua y vacía de contenido el concepto de fuero militar. La estructura de nuestro Estado fundado en el principio de Dignidad Humana aboga por un derecho penal garantista liberal, concebido como un derecho penal de ciudadano y de ello no puede ser ajeno el Derecho Penal militar; en esa dimensión entendemos y compartimos el proyecto, pues no quisiéramos ni pensar que en nuestro Estado democrático las dificultades interpretativas que hoy tenemos y que avocan la reforma, la inseguridad jurídica que actualmente se pregona por algunos, encuentren razón en la formulación, construcción y consecuencia de un Derecho Penal de enemigo. Tal hipótesis ni siquiera la concebimos.

En principio consideramos que el problema es de interpretación, o para un mejor decir, de un inadecuado análisis, en consecuencia

${ }^{3}$ Constante que se aprecia desde la Constitución de 1832. 
la problemática no la suscita la ausencia de norma, máxime cuando la Corte Constitucional en sentencias C-358 de 1997 y C878 de 2000 precisó que la relación con el servicio corresponde a la multiplicidad de tareas que desempeña el miembro de la Fuerza Pública para alcanzar la finalidad constitucional, al respecto enseñó la Corte: "el servicio lo comportan la multiplicidad de tareas, objetivos, menesteres y acciones que resultan necesarias para emprender con miras a cumplir la función constitucional y legal que justifica la existencia de la fuerza publica". Lo que permite inferir que el acto del servicio comporta actividades de instrucción, entrenamiento, incorporación, capacitación, inteligencia, labores logísticas, administrativas y lo operacional por solo citar algunos aspectos.

Ahora bien, la dinámica del conflicto hace que la fuerza militar y policial —en el ejercicio de la función el miembro de la Fuerza Pública - se pueda ver involucrada en la realización de delitos comunes que también son de conocimiento de la Justicia Penal Militar como lo prevé la ley penal militar y lo precisó la Corte Constitucional, al declarar la exequibilidad del artículo 195 de la ley 522 de 1999, mediante sentencia C-878 de 2000, y hoy el artículo 171 de la Ley 1407 de 2010. Allí, la Alta Corporación no hizo distinción alguna, ni el legislador, salvo lo dispuesto en el artículo $3^{\circ}$ de las citadas leyes y que tiene que ver con tortura, genocidio, desaparición forzada y crímenes de lesa humanidad. Lo enunciado no genera dificultad interpretativa, salvo los efectos del in dubio pro jurisdicción que estableció la referida sentencia C-358 de 1997, en la que se dispuso que al surgir la duda fundada, ésta se resuelve en favor de la justicia ordinaria, postulado que en la praxis genera significativas dificultades para su comprensión, a más que a veces se comprometen en el juicio de competencia valoraciones de responsabilidad que pueden conspirar contra el principio de presunción de inocencia.

Bajo este entendido surgen aquí dos elementos fundamentales que desarrollan y materializan lo planteado: uno, corresponde a la condición particular del ejercicio de la función que cumple la Institución, lo que conlleva a la existencia del fuero militar para quienes fungen en ella; y, lo segundo, la necesaria actuación de una jurisdicción especializada, que por esa exclusiva función de los destinatarios de la norma, requiere un conocimiento especial ajeno a la vida civil, un juez militar que se constituye en verdadero juez natural, y de contera es la jurisdicción castrense la llamada a 
investigar y a juzgar la conducta de tales servidores. Esa jurisdicción especializada, y me estoy refiriendo obviamente a la penal militar, es la convocada a revisar las conductas típicas relacionadas con el servicio y, a partir de este entendido, podemos afirmar que a más de los delitos especiales y comunes, la vigencia del fuero militar en una realidad como la colombiana se ha de explicar en el contexto del conflicto interno a partir de la aplicación del Derecho Internacional Humanitario.

Otro aspecto que suscita dificultad es el derivado de lo establecido en el artículo 3 de la Ley 1407 de 2010, nuevo Código Penal Militar, que consagró entre otras limitantes a la competencia de la justicia castrense, el no conocer de delitos contra el Derecho Internacional Humanitario $^{4}$. Esta dificultad es resuelta con la iniciativa que presenta el Acto Legislativo No. 16 Senado, 192 Cámara, en la modificación del artículo 221 de la Carta Política al otorgarle el conocimiento de las infracciones al DIH, de los tipos penales consagrados en el Título II del Código Penal Militar a la jurisdicción penal militar.

No podemos dejar de reseñar en este calificado auditorio, que si bien es cierto el artículo 116 Constitucional estableció la jurisdicción militar y le reconoció su facultad de administrar justicia, también lo es, que la propia Carta Política no desarrolló tal jurisdicción, como si lo hizo con otros entes que administran justicia, v.gr., los dispuestos en los arts. 235 a 246 . Tal vacío conlleva a la dificultad interpretativa que hoy existe en punto del derecho aplicable al miembro de la Fuerza Pública comprometido en una operación militar; de igual forma, respecto de las reglas de interpretación del Derecho Internacional con el Derecho interno, su armonización, el juicio de imputación y la definición de competencia para conocer del asunto; vacío que de alguna manera ha venido siendo cubierto por los diferentes pronunciamientos jurisprudenciales, en particular de la Corte Constitucional.

Ahora bien, en cuanto hace al proyecto de Acto Legislativo de 2012 No. 16 Senado y 192 Cámara, encontramos su justificación en lo expresado en precedencia, a más de la reflexión que nos suscita el hecho que si el actual canon 221 Superior fuera suficiente, no se vería un Estado en conflicto avocado a modificar su Constitución para precisar el alcance del fuero, de la jurisdicción militar, del derecho atribuible al miembro de la Fuerza Pública y determinar

${ }^{4}$ Sentencias C-533 de 2008 y C- 469 de 2009. 
unas reglas de aplicación e interpretación; estamos convencidos de que la reforma es necesaria y que ella debe consultar la necesidad de justicia que reclama nuestro país.

Prevé el referido Acto Legislativo la creación de un Tribunal de Garantías Penales que tendrá competencia en todo el territorio nacional y en cualquier jurisdicción penal, el cual ejercerá como funciones de manera preferente, servir de juez de control de garantías en cualquier investigación o proceso penal que se adelante en disfavor de miembros de la Fuerza Pública. Asimismo, controlará la acusación penal contra éstos con el fin de asegurar que se cumplan los presupuestos materiales y formales para iniciar el juicio oral. Nuestra observación apunta al riesgo que se genera con el nuevo instituto, de resquebrajar la estructura del proceso penal, tanto ordinario como militar, diseñados bajo la comprensión adversarial de partes, en el cual la Fiscalía (ordinaria o militar) es titular de la acción, y en la que se pregona la existencia de un juez "imparcial" en el entendido que no se involucra en la actuación sino hasta el juicio donde conoce los hechos, las evidencias y en tal desarrollo, a partir de los principios de concentración e inmediación, toma la decisión. Pero al otorgar al Tribunal la facultad de verificar toda la actuación que surge de las audiencias preliminares y a la vez efectuar el control material a la acusación, se está otorgando una doble función que desequilibra el sistema, generando igualmente dificultad para el trámite de un recurso contra sus decisiones y corriendo el riesgo de defraudar la doble instancia. Estimamos que se estaría despojando al juez de conocimiento de su competencia y con ello fracturando la esencia del modelo procesal que se pretende. Avizoramos, igualmente, dificultades en punto del principio de igualdad ante la ley.

Por ello, respetuosamente sugerimos que el Tribunal sólo debería ocuparse de las audiencias preliminares, pero rescatamos y compartimos que de manera permanente, dirimirá los conflictos de competencia que ocurran entre las Jurisdicciones Ordinaria y Penal Militar, mas precisando que en su conformación, como se expresa, deben estar miembros de la Fuerza Pública expertos en temas militares y Justicia Penal Militar, máxime si se atiende el nivel que se le otorgará a dicha Corporación. Sin duda, esta propuesta soluciona el vacío que hoy existe para resolver un conflicto de competencias entre jurisdicciones, toda vez que los artículos 54 de la Ley 906 de 2004 y 274 de la Ley 522 de 1999, fueron diseñados para remediar el conflicto al interior de las jurisdicciones, pero no cuando éstas se enfrentan. 
En cuanto hace al artículo 221, hemos venido señalando que sería adecuado que se indicara que de las conductas cometidas por los miembros de la fuerza Pública en servicio activo y en relación con el servicio, serán investigadas y juzgadas por la Justicia Penal Militar y precisar su integración así: el Tribunal Superior Militar, las Cortes marciales, los Jueces Penales Militares de Conocimiento, los Jueces Penales Militares de Control de Garantías, los Jueces Penales Militares de Ejecución de Penas y Medidas de Seguridad y la Fiscalía General Penal Militar, tal y como fue concebido en el nuevo Código Penal Militar, Ley 1407 de 2010.

En ese sentido proponemos que el primer inciso del artejo 221 Superior, quede redactado así: "Los delitos cometidos por los miembros de la Fuerza Pública en servicio activo, y en relación con el mismo servicio, serán investigados y juzgados por la justicia penal militar y policial, la cual estará integrada por los Tribunales militares y policiales, las cortes marciales, los jueces penales militares de conocimiento, los jueces penales militares de control de garantías, jueces penales militares de ejecución de penas y medidas de seguridad, la fiscalía general penal militar y su cuerpo técnico de investigación, con arreglo a las prescripciones del Código Penal Militar y policial. Tales cortes o tribunales estarán integrados por miembros de la Fuerza Pública abogados, en servicio activo o en retiro".

En cuanto se refiere al catálogo delictivo nos parece más adecuada la redacción que se propuso en el segundo debate por ser más técnica en el sentido que una Constitución no se ocupe de lo que debe determinar la ley. Dejando claro que en punto de las denominadas "ejecuciones extrajudiciales" merece nuestro reparo por prevalencia del principio de legalidad. Destacamos que consigne que las infracciones al Derecho Internacional Humanitario cometidas por miembros de la Fuerza Pública sean conocidas exclusivamente por las cortes marciales o tribunales militares, toda vez que, como se expuso en precedencia, nada más relacionado y connatural a la función militar en el marco de las operaciones militares orientadas a enfrentar un adversario dentro de un conflicto interno, que las operaciones militares y en ellas la aplicación del Derecho Internación Humanitario; por manera que si el elemento objetivo del fuero se deriva de la actividad propia del servicio, per se lícita, su desborde o extralimitación han de ser conocidas por la justicia militar. Comprendido, eso si, que lo que forma parte del núcleo duro del Derecho Internacional Humanitario, estaría fuera del ámbito de competencia al que se alude, esto es, delitos de genocidio, tortura, desaparición forzada, etc. En este entendido, si se dispone 
que una ley especificará sus reglas de interpretación y aplicación, y determinará la forma de armonizar el Derecho Penal con el Derecho Internacional Humanitario, llamamos la atención y pedimos tener tal cuidado en su redacción para que no se limite el ejercicio legítimo de la Fuerza Pública, sobre todo en un país tan cambiante y con toda una diversidad de expresiones y formas de violencia, para que no se afecte y limite el principio de flexibilidad de la operación militar, $y$, de otra parte, que se dé margen razonable y ponderado de interpretación al juez.

En cuanto a la comisión técnica de coordinación integrada por representantes de la jurisdicción penal militar y de la jurisdicción penal ordinaria, apoyada por sus respectivos órganos de policía judicial, encontramos que los modelos procesales diseñados en la Ley 906 de 2004 y en la Ley 1407 de 2010, se caracteriza porque la investigación es adelantada por la policía judicial, el fiscal la dirige pero no se involucra en las escenas, menos aún en el recaudo, si esto es así, como en efecto lo es, no se ve claro cómo actuaría la comisión técnica de coordinación que se propone sin que afecte lo señalado, la cadena de custodia, los actos urgentes y el principio de legalidad y oficiosidad que tienen tanto el fiscalía militar o fiscalía de la justicia ordinaria dentro del ámbito de su competencia de investigar y perseguir.

Enfatizamos: todo lo que se haga por generar mejores y óptimas condiciones de autonomía e imparcialidad de la Justicia Penal Militar, toda vez que desde el año 2000 con la Ley 522 de 1999, en la que se separó la jurisdicción especializada de la línea de mando, el Decreto 1790 de 2000 y la Ley 940 de 2005, se ha procurado porque dicha jurisdicción sea cada vez mas autónoma e independiente, así la comprensión de una estructura y un sistema de carrera propio e independiente del mando institucional resultan de buen recibo para el sistema de administración de justicia.

De buen recibo resulta la creación del fondo propuesto específicamente para financiar el Sistema de Defensa Técnica y Especializada de los miembros de la Fuerza Pública, toda vez que esta jurisdicción y los destinatarios de la norma carecen de una efectiva defensa técnica calificada, oportuna y eficaz (Defensor abogado, Ley 1407 de 2010). En igual sentido nos pronunciamos respecto del denominado fuero carcelario que ratifica — pues ya lo había establecido la ley, pero la praxis demuestra que no se atiende- que los miembros de la Fuerza Pública cumplan la detención preventiva en centros de 
reclusión establecidos para ellos y, a falta de éstos, en las instalaciones de la Unidad a que pertenezcan y que cumplan la condena en centros penitenciarios y carcelarios destinados para integrantes de las Fuerzas Militares y la Policía Nacional.

La norma transitoria que forma parte del proyecto en el artículo $4^{\circ}$, nos merece reparo, no aquella que dispone que los procesos penales que se adelanten contra los miembros de la Fuerza Pública por los delitos enunciados en el artículo $3^{\circ}$ del presente acto legislativo y que se encuentren en la justicia ordinaria, continuarán en ésta, sino el aparte que determina: "Los demás delitos continuarán en la justicia ordinaria hasta que se expida la ley estatutaria", toda vez que consideramos conlleva a excluir la competencia de la justicia militar en delitos comunes que se cometen en relación con el servicio, como lo prevé el canon 195 de la Ley 522 de 1999 declarado exequible por la sentencia C-878 de 2000 y el artículo 171 de la Ley 1407 de 2010; de igual manera, se desconoce el postulado que busca precisar el juez natural, el juez competente, a través del fenómeno de la colisión de competencia.

Un estado democrático, con un programa demoliberal de Derecho Penal, debe generar las condiciones óptimas para brindar seguridad jurídica a los asociados, para el caso que nos convoca, al miembro de la Fuerza Pública; bajo ese entendido, compartimos la modificación que se propone a los artículos 116, 152 y 221 de la Carta Política, pero, con los reparos planteados y ajustes que respetuosamente formulamos, con la única pretensión de mejorar el proyecto, hacerlo más eficaz, de tal manera que genere seguridad jurídica, propenda por la efectiva realización de la justicia material y consulte el programa de Derecho Penal en un Estado Social y Democrático de Derecho, fundado en la superación del vetusto Derecho Penal de autor y dando paso al Derecho Penal de acto, etc. Por manera que concebimos el proyecto como toda una novedosa construcción normativa, que permitirá a la administración de justicia militar $u$ ordinaria examinar la conducta del miembro de la Fuerza Pública bajo los contenidos y el rigor de un derecho penal de ciudadano; en esa dimensión entendemos y compartimos el proyecto.

\footnotetext{
${ }^{5}$ Recuérdese que, tras el séptimo debate, cambió el tenor literal: "Los procesos penales que se adelanten contra los miembros de la Fuerza Pública por los delitos expresamente excluidos del conocimiento de la Justicia Penal Militar en el inciso $2^{\circ}$ del artículo $3^{\circ}$ del presente acto legislativo y que se encuentren en la justicia ordinaria, continuarán en esta" (Nota del Director).
} 